\title{
Who has Australia's most-followed Twitter accounts in health and medicine?
}

\author{
Simon Chapman ${ }^{a, b}$ and Becky Freeman ${ }^{a}$ \\ a School of Public Health, University of Sydney, NSW, Australia \\ b Corresponding author: simon.chapman@sydney.edu.au
}

\section{Article history}

Publication date: July 2015

Citation: Chapman S, Freeman B. Who has Australia's most-followed Twitter accounts in health and medicine? Public Health Res Pract. 2015;25(3):e2531534. doi: http:// dx.doi.org/10.17061/phrp2531534

\section{Key points}

- Twitter followings of leading health nongovernment organisations and government departments are generally far higher than those for leading individuals

- Leading individual Twitter accounts with a single-issue focus generally have far higher followings than leading individuals who tweet on a variety of health issues

- Of the 10 most followed single-issue individual accounts, three campaigned against sugar, two were about nutrition, and two about personal fitness

\section{Abstract}

Twitter is a social media platform that can be used by people working in health and medicine to distribute information, advocate, debate and network with large numbers of other users.

We set out to determine the top 10 Australian Twitter accounts in four categories, ranked by number of Twitter followers. We extracted names with high follower volumes from 'lists' of health and medical Twitter accounts, and then 'crowdsourced' on Twitter for names that were not included on those lists.

Individuals tweeting on single-issue topics (especially sugar, nutrition and fitness), health institutions, and people working in the media had higher Twitter followings and lower tweet-to-follower ratios than those tweeting on mixed health topics. Tweeting pictures was nominated by several as a way of attracting retweets. Highly followed Twitter users expressed a variety of benefits of using Twitter.

\section{Introduction}

The social media platform Twitter was created in March 2006 and by July 2014 had 645.75 million active users ${ }^{1}$, with some 2.8 million Twitter accounts in Australia. ${ }^{2}$ An estimated 500 million Twitter messages, or 'tweets', in 35 languages are sent out every day. ${ }^{3}$ Tweets are limited to 140 characters, but users can add web links, pictures and videos to tweets. Tweets appear in the Twitter feeds of followers and are most commonly viewed on mobile devices.

Twitter users can follow other account holders and further disseminate tweets by sharing or 'retweeting' to their follower networks. Twitter also enables users to mention other users in tweets by tagging their unique Twitter name, known as a 'handle'. Users commonly include hashtags (e.g. \#tobacco) so that other users who do not follow their account can readily search for relevant tweets on topics of interest. Users can also 'favourite' tweets they like and create lists of preferred accounts.

Twitter can be used for disseminating links to research and information, for commentary and discussion, and for mobilising activists. ${ }^{4}$ Twitter is a favoured platform among journalists and has been used to rapidly spread 
news about emerging global issues. ${ }^{5}$ Like most other social media, advertising revenue generation is required in lieu of user fees for it to be viable, and companies can purchase promoted tweets that appear in targeted user Twitter feeds.

There is growing scholarly interest in how Twitter covers a variety of health and medical issues, and in how people working in these areas use Twitter for information dissemination, advocacy, networking and debate. On 11 May 2015, a PubMed search for 'Twitter' returned 758 articles with this word in the title or abstract.

In this paper, we report on the most-followed Australian Twitter accounts in the health and medical fields on that day, and provide comments by 10 individuals about their most-retweeted and impactful tweets. We define a health or medical focus as including tweets that related to named health problems, issues or determinants, with the latter needing to be linked directly to health to be included.

\section{Method}

We set out to determine the top 10 Australian Twitter accounts in health and medicine, ranked by number of followers, in four categories: 1) individuals tweeting about multiple health issues; 2) individuals tweeting about single-focus areas (e.g. diet, physical activity, surgery, emergency medicine); 3) health agencies and politicians; and 4) journalists, presenters and publications tweeting about health and medicine. We were interested in users who tweeted often about health and medicine, not in doctors or health workers who tweeted mainly about nonhealth issues.

Because of the great diversity of health issues, and because many individuals who tweet about health issues also tweet about many other matters, no conceivable search string could be used to locate all possible candidates for 'top tweeters'. To try to locate the mostfollowed accounts, we initially searched through several lists of health and medical Twitter accounts and manually extracted those with high followings. We progressively discarded those who fell out of the top 10 for each of the four categories. Some users posted often about nonhealth or nonmedical issues, particularly about science (such as @DoctorKarl, 249860 followers; and @dr_krystal, 5183 followers). We eliminated anyone who tweeted less than $30 \%$ of their tweets about health and medical issues, determined from examining their 50 most recent tweets and replies. We also eliminated one person whose following contained many fake accounts (@GeorgeDiasDoc, 61895 'followers'). We circulated the provisional final lists to the people ranked in the top 10 and asked them to notify us of any highly followed Twitter accounts we may have missed. Finally, we 'crowdsourced' suggestions by posting on Twitter the number of people following accounts that were provisionally ranked 10th in each of the four categories and requested readers to send us any accounts that had higher followings. This produced several names that had not been considered. It is possible that there were other accounts with higher followings than the 10th most-followed accounts in our table, but we know of no way of bringing these to light other than by the method we used. There is no exhaustive 'list' of Twitter accounts categorised by subject matter. Rather, word of highly followed accounts spreads among active Twitter users and these accounts become top-of-mind to those interested in those fields.

We invited each person in the 'individual (multifocus)' group (group 1 above) to nominate one example of a tweet they had sent that had received a large number of retweets and favourites, and one example of another tweet that had led to some important outcome. Some also replied with more general statements about the value of Twitter.

\section{Results}

\section{Top tweeters}

We calculated tweet-to-follower ratios and average tweets per day since each account was opened, for all accounts (Table 1).

\section{Comments from leading users}

\section{Ben Harris-Roxas (health evaluation consultant and communicator)}

Biggest retweet: "A tweet about the supposed visual impact of wind turbines, in this case near a coal mine in Germany" (twitter.com/ben_hr/ status/433202435503312897, 822 retweets, 338 favourites).

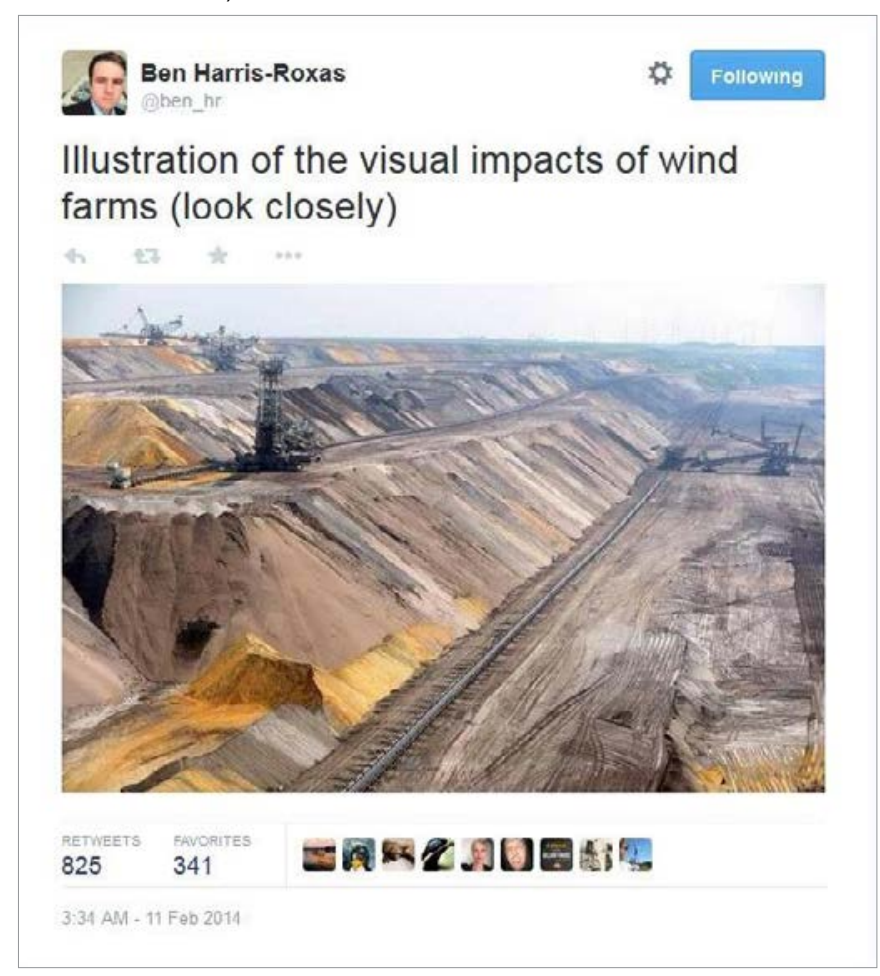


Table 1. Top 10 users in four categories, ranked by number of followers

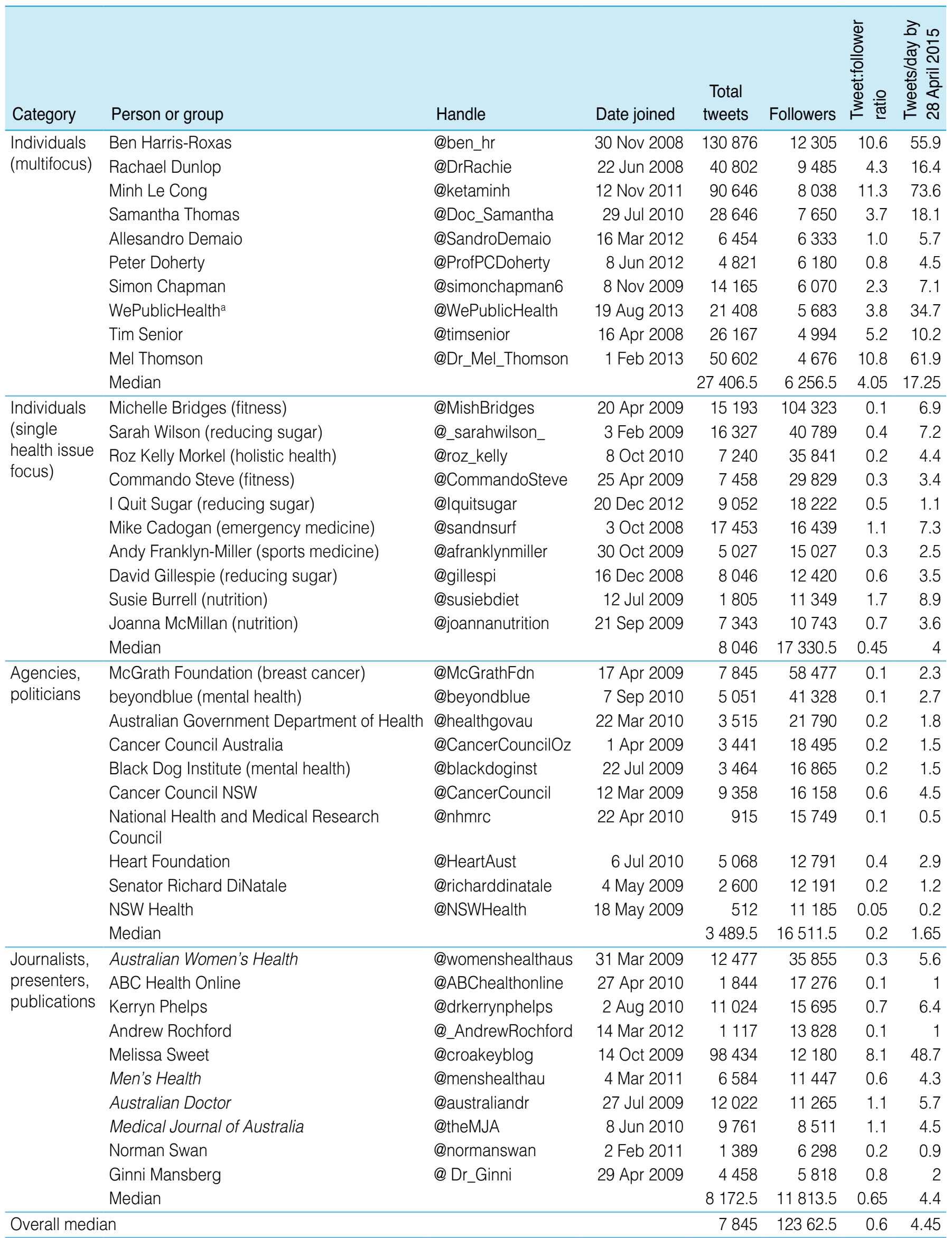

a @WePublicHealth has many different guest tweeters.

Source: Twitter.com, 28 April 2015 
Biggest impact: "Getting direct responses from both the then Premier and Leader of the Opposition to questions about NSW Area Health Service mergers."

\section{Rachael Dunlop (medical researcher and academic)}

Biggest retweet: "One of my biggest retweets was a link to an article with the headline 'Homeopathy product recalled over fears it may contain actual medicine'" (twitter.com/ DrRachie/status/449028261578698752?s=17, 116 retweets, 35 favourites).

Biggest impact: "I have a reputation for being outspoken about vaccination, and many of my antiantivaccination rants have been picked up by journalists who have then asked me to write articles for their publications. One such piece, 'Six myths about vaccination and why they're wrong', was originally published in The Conversation and has now been read more than 800000 times. It was republished in The Sydney Morning Herald, The New Zealand Herald, on Life Hacker, by AusMed Education, SBS News and as a book chapter in The explainer: from deja vu to why the sky is blue and other conundrums, as well as 99 \& counting medical myths debunked. A similar piece for Mamamia titled 'Cheat sheet, 9 vaccination myths busted. With science!' has been shared on Facebook 19800 times, tweeted 924 times and 'pinned' on Pinterest 136 times."

\section{Samantha Thomas (public health researcher and academic)}

Biggest retweet: "Most of my larger retweets have related in some way to commentary about [gambling] industry tactics, or vulnerability (or a combination of both)" (twitter.com/ Doc_Samantha/status/479197396845334530, 48 retweets).

Biggest impact: "This has been the way in which I have been able to use Twitter to draw attention to the tactics of the gambling industry and gambling harm. I have used Twitter to share articles, highlight the defunding of gambling advocacy organisations and engage with MPs about gambling harm. For example, my article on The Hoopla about gambling harm was retweeted 93 times by gambling organisations all over the world. When the Problem Gambling Foundation of New Zealand lost the majority of its funding, I engaged with NZ Minister Peter Dunne in a public conversation about the reason for this" (twitter.com/Doc_Samantha/status/447829453251416064).

\section{Minh Le Cong (general practitioner with the Royal} Flying Doctor Service)

"\#FOAMed is a movement of like-minded health professionals who fundamentally subscribe to the ethos that shared learning is an ethical duty. To me Twitter provides an immensely powerful network capability for the rural and remote health professional that crosses not only professional disciplines but spans across the whole community at multiple levels. I can interact with not only rural nurses and doctors but paramedics and community leaders. You never have to feel isolated in remote Australia. The world is talking and Twitter is how you listen."

\section{Alessandro Demaio (public health researcher and academic)}

Biggest retweet: "The richest $1 \%$ now hold half of global wealth - says new report. \#Inequality threatens us all' (twitter.com/SandroDemaio/status/522314377358479360, more than 170 retweets). To me this shows the growing concern and frustration at economic inequality in our societies, and recognition that it threatens the very social fabric we have worked so hard to create.

"A close second was a photo of a road sign in the US I drove past - the top sign was 'left for McDonalds', the one below was 'right for dialysis'. I think humour is a powerful tool for social protest."

Biggest impact: "I think the biggest impact is to be made through combining Twitter with other forms of online media. I use it regularly to disseminate my blog posts, column articles, updates from NCDFREE, our short films and even open access journal publications. To me, this is a very effective way to communicate to a wider audience reaching out from what can easily become the ivory tower of academia."

\section{Melissa Sweet (health journalist and author)}

"For me, one of the most important consequences of my Twitter immersion has been the transformative learning it has brought about Indigenous health and Indigenous affairs more broadly, through being able to hear from a diverse range of Aboriginal and Torres Strait Islander people in a way that has never been possible before, certainly not via the mainstream media. This has been profound for me at both a professional and a personal level."

\section{Simon Chapman (public health researcher and academic)}

Biggest retweet: "I tweeted a photo of wind turbines on the horizon near a large power station (twitter.com/ simonchapman6/status/472132442032054272) shortly after Australian Treasurer Joe Hockey made disparaging remarks about wind turbines being ugly, in late May 2014 (2322 retweets, 1112 favourites). It just keeps on being shared even 12 months later."

Biggest impact: "Days after the 14 December 2012 Sandy Hook firearm massacre in the US, I tweeted a link to a 2006 research paper of mine ${ }^{6}$, showing the impact of Australia's 1996 gun law reforms. Before my tweet, the paper had received 17133 opens. In December 2012 it was opened 82561 times, and has now been cited 112 times."

\section{Peter Doherty (Nobel Prize winning medical researcher)}

"As often happens with senior scientists, my interests are very broad and l've written 'lay' books addressing issues as diverse as pandemic infections, birds monitoring the [health of the natural] world, climate change and the scientific life. Aiming for greater sales, Melbourne University Publishing started me down the Twitter road. For a while, I largely 
ignored it, then realised that tweeting offers a mechanism for bringing interesting articles and ideas l'd encountered to the attention of others. That sometimes attracts critical, and even hostile, responses. Replying helps me to understand better the position, strengths and limitations of others, and allows me to test viewpoints to see how (or if) they resonate. I'm an experimentalist by training and practice and Twitter allows me to do 'experiments' - some of the 'results' of those experiments are already influencing how I write for a broader audience."

\section{Tim Senior (general practitioner working in Aboriginal health)}

Biggest retweet: "This was a tweet I posted in the midst of the debate about the proposed Medicare co-payment, when Joe Hockey, the Federal Treasurer, compared the cost to cigarettes and beer. ${ }^{7}$ I tweeted 'Dear @ JoeHockey can you advise my patients who can't afford $\$ 7$ and don't drink/smoke what they should give up? Feeding the children perhaps?'" (twitter.com/timsenior/ status/466779311215620097, 450 retweets, 256 favourites).

"A close runner-up was a tweet comparing the raised retirement age with Aboriginal and Torres Strait Islander life expectancy" (twitter.com/timsenior/ status/454782076223369216, 434 retweets)."

Biggest impact: "My use of Twitter has allowed me to have conversations with people I would never normally come across, such as one ${ }^{8}$ with Terry Barnes, the policy consultant who opened up the current debate on the Medicare co-payment.

"More significant personally, has been the way Twitter has allowed me to crowdfund a series of articles for Croakey on the likely health effects of government policy, essentially a social determinants of health commentary for an intelligent lay audience. This has enabled a wider audience for concepts of social determinants, as well as shown a potential model for funding health writing. This has only been possible through a generous and highly engaged audience based mostly around Twitter."9

\section{Mel Thomson (medical researcher and academic)}

Biggest retweet: "On 28 August 2014 I tweeted about the first US citizen to survive Ebola infection (Dr Brantley) who attributed his recovery to the power of prayer: twitter.com/ Dr_Mel_Thomson/status/503039074551480320/photo/1. My tweet questioned this and asked if the researchers developing a newly developed drug (which he had been given, among a suite of other evidence based medical interventions) deserved any credit, as well as a higher power (117 retweets, 69 favourites). Mostly due to the amplification of the signal by Edvard Ernst, a major international player in the Skeptics scene, who follows my account, many God-fearing trolls then targeted me for abuse, although I had not questioned the existence of God or the power of prayer, just that the role of medical research should also be given fair acknowledgement."

Biggest impact: "On 4 June 2014, I found that a local Geelong Innovation event, sponsored by my employer, had an all-male speaker line-up. As a known advocate for women in innovation industries (such as medical biotechnology, engineering and technology) I expressed my disappointment on Twitter that my own employer (who had strict equality and diversity policies) would sponsor such a biased event.

"Members of the local news print media picked up the story wanting to interview me about the issue. I had to ask permission to give the interview from the media representatives of the employer that I had criticised, which went to the very highest level. My employer supported my position and was quoted in the article. An article on this Twitter furore was published in the Geelong Advertiser and I was then contacted by the head of my organisation, who gave me both the job of heading a new Women in Science committee internally and a position on the newly formed national Women in Science Australia committee."

\section{Discussion}

Because we only listed the top 10 most-followed users in four categories, it is not sensible to make generalisations from their Twitter data nor possible to compare their tweeting practices with users at large. However, several observations are noteworthy when comparing the four different categories.

The median tweet-to-follower ratios of the leading individuals with multiple areas of focus were uniformly much higher than those across the other three tweeter categories. The median tweet volumes of these 'multifocus' individuals were more than three times greater than those made by specialised individual users, nearly four times higher than the journalists, presenters and publications group, and nearly eight times greater than the tweet volumes of those in the agencies and politicians category. This was only partly explained by two of the multifocused individuals having very large tweet volumes.

The multifocus individual group also had a far lower median follower volume than the other three groups. It would appear that far more users interested in health issues follow prominent agencies, politicians and individuals working in the media than even well-followed multi-issue focused individuals. The obvious exceptions here can be seen in the individual single-issue focus category. This category was dominated by weight loss and nutrition specialists (seven of the ten, including three sugar avoidance specialists), and the seven highest followed of these accounts would have made it into the top 10 agency list if they had been agencies. The agencies/politicians group had the lowest median tweets per day, with four sending very few tweets but having large followings (McGrath Foundation, beyondblue, National Health and Medical Research Council and NSW Health).

A common theme among those who we asked to comment on the impact of their Twitter activity was the ability to either reach out to politicians or to contribute to the reframing of political debate about controversial public 
health issues. This ability to connect with and gain the attention of politicians is essential for advancing public health advocacy. ${ }^{10}$ Twitter enables immediate commentary and outreach without news editors, political staff or bureaucrats acting as gatekeepers between advocates and politicians. Users in our sample were also skilled at introducing popular arguments and counterframes to policy agendas that had neglected public health goals or perspectives.

Tweets that include an image are more likely to be retweeted, quoted and favourited. ${ }^{11}$ Our sample showed evidence of this, with two users identifying a photo-based tweet as their most popular tweet. Coincidentally, both users shared different images of wind farms juxtaposed against fossil fuel power production. Given that both users are part of the Australian public health community on Twitter, it suggests there is an opportunity for more formal coordination or collaboration across Twitter about issues that resonate with followers. Just as health coalitions work together to develop and disseminate key messages through traditional media, this approach could be better applied to Twitter. Health advocates need to consider extending key messages beyond text and including shareable and compelling images.

Connecting with other users, giving voice to groups and issues that are normally ignored in the mainstream press, and demonstrating leadership of neglected public health issues were all highlighted by top tweeters as key Twitter impacts. Users achieved this by sharing links to their own research, actively engaging with other users and lending their profiles to lesser-known users by sharing tweets and creating opportunities for other users to attract more followers. ${ }^{12}$ Although Twitter is often the subject of news headlines for negative reasons, particularly the abuse that users sometimes suffer at the hands of 'trolls', it is clear that the high-ranked users in our sample continue to regard Twitter as a positive and important public health tool.

\section{Competing interests}

None declared

\section{Author contributions}

SC and BF both conceived the study; both researched it and wrote it.

\section{References}

1. Statistic Brain Research Institute. Twitter statistics; 2015 [cited 2014 Jul 11]. Available from: www.statisticbrain. com/twitter-statistics/

2. Bochenski N. Twitter 2.8 million users in Australia; 2014 Aug 4 [cited 2015 Jun 2]. Available from: www. brisbanetimes.com.au/digital-life/digital-life-news/twitter28-million-users-in-australia-20140804-1009op.html

3. Twitter. Company: Twitter usage/company facts; 2014 [cited 2014 Oct 21]. Available from: about.twitter.com/ company

4. Tufekci Z. \#Bringbackourgirls and the complexities of attention. The Message. 2014 [cited 2014 Oct 20]. Available from: medium.com/message/bringbackourgirlsand-the-complexities-of-attention-3c3ab5d1dc0e

5. Jewell J. How Twitter has helped the emergence of a new journalism. The Conversation. 2013 Nov 5 [cited 2015 Jun 2]. Available from: theconversation.com/ how-twitter-has-helped-the-emergence-of-a-newjournalism-19841

6. Chapman S, Alpers P, Agho K, Jones M. Australia's 1996 gun law reforms: faster falls in firearm deaths, firearm suicides, and a decade without mass shootings. Inj Prev. 2006;12:365-72.

7. Knott M. Less than two middies: Joe Hockey defends $\$ 7$ GP fee. Sydney Morning Herald; 2014 May 14 [cited 2015 June 2]. Available from: www.smh.com.au/federalpolitics/political-news/less-than-two-middies-joe-hockeydefends-7-gp-fee-20140515-zrdb6.html

8. Senior T. When Terry Barnes and I bumped into each other on Twitter. Storify.com; 2014 Jun [cited 2015 Jun 2]. Available from: iofthet.blogspot.com.au/2014/03/whenterry-barnes-and-i-bumped-into.html

9. Crikey. Wonky Health; 2015 [cited 2015 Jun 2]. Available from: blogs.crikey.com.au/croakey/wonky-health/

10. Chapman S. Reflections on a 38-year career in public health advocacy: 10 pieces of advice to early career researchers and advocates. Public Health Res Pract. 2015;25(2):e2521514

11. Zarella D. Dan Zarella: the social media scientist. Use images on Twitter to get more retweets; undated [cited 2015 Jun 5]. Available from: danzarrella.com/use-imageson-twitter-to-get-more-retweets.html\#

12. Freeman B, Potente S, Rock V, Mclver J. Social media campaigns that make a difference: what can public health learn from the corporate sector and other social change marketers? Public Health Res Pract. 2015;25(2):e2521517

\section{Copyright: (cc) (1) $\$$ BY}

(C) 2015 Chapman and Freeman. This article is licensed under the Creative Commons Attribution-NonCommercial-ShareAlike 4.0 Internationa Licence, which allows others to redistribute, adapt and share this work non-commercially provided they attribute the work and any adapted version of it is distributed under the same Creative Commons licence terms. See: www.creativecommons.org/licenses/by-nc-sa/4.0/ 